\title{
Induction of ROS, p53, p21 in DEHP- and MEHP-exposed LNCaP cells-protection by selenium compounds
}

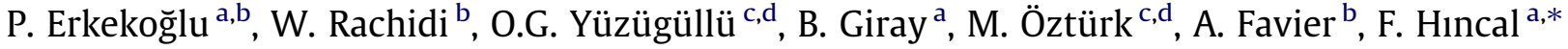 \\ ${ }^{a}$ Hacettepe University, Faculty of Pharmacy, Department of Toxicology, 06100 Ankara, Turkey \\ ${ }^{\mathrm{b}}$ CEA Grenoble, INAC/SCIB/LAN, 17 Rue des Martyrs, 38054 Grenoble Cedex 9, France \\ c Department of Molecular Biology and Genetics, Bilkent University, 06800 Ankara, Turkey \\ ${ }^{\mathrm{d}}$ Centre de Recherche INSERM-Université Joseph Fourrier U823, Institut Albert Bonniot, 38042 Grenoble, France
}

\section{A R T I C L E I N F O}

\section{Article history:}

Received 30 December 2010

Accepted 4 April 2011

Available online 15 April 2011

\section{Keywords:}

DEHP

MEHP

p53

p21

ROS

Selenium

\begin{abstract}
A B S T R A C T
This study was designed to investigate the hypothesis that the toxic effects of di(2-ethylhexyl)phthalate (DEHP), the most abundantly used plasticizer and ubiquitous environmental contaminant that cause alterations in endocrine and spermatogenic functions in animals is mediated through the induction of reactive oxygen species (ROS) and activation of nuclear p53 and p21 proteins in LNCaP human prostate adenocarcinoma cell line. Protective effects of two selenocompounds, sodium selenite (SS) and selenomethionine (SM) were also examined. It was demonstrated that $24 \mathrm{~h}$ exposure of the cells to $3 \mathrm{mM}$ DEHP or its main metabolite, mono(2-ethylhexyl)phthalate (MEHP, $3 \mu \mathrm{M}$ ) caused strongly amplified production of ROS. Both SS (30 nM) and SM $(10 \mu \mathrm{M})$ supplementations reduced ROS production, and p53 and p21 activation that induced significantly only by MEHP-exposure. The overall results of this study indicated that the induction of oxidative stress is one of the important mechanisms underlying the toxicity of DEHP and this is mainly through the effects of the metabolite, MEHP. Generated data also emphasized the critical role of Se in modulation of intracellular redox status, implicating the importance of the appropriate Se status in cellular response against testicular toxicity of phthalates.
\end{abstract}

(c) 2011 Elsevier Ltd. All rights reserved.

\section{Introduction}

The tumor suppressor protein p53 is a transcription factor controlling cell cycle progression, cell survival, and DNA repair in cells exposed to genotoxic as well as non-genotoxic stresses (Hainaut and Hollstein, 2000; Pluquet and Hainaut, 2001). p53 is constitutively expressed in a latent form in most cells and tissues. Exposure to DNA-damage induces p53 to accumulate in the nucleus in an active form with high affinity for specific DNA sequences, after posttranslational modifications at both $\mathrm{N}$ and $\mathrm{C}$ terminus of the protein (Pluquet and Hainaut, 2001). Activated p53 binds to DNA and regulates the transcription of several sets of target genes, including

Abbreviations: CM- $\mathrm{H}_{2}$ DCFA, 5-(and 6-) chloromethyl-2',7'-dichlorodihydrofluorescein diacetate; DAB, 3,3'-diaminobenzidine; DCF, 2',7'-dichlorofluorescein; DEHP, di(2-ethylhexyl)phthalate; DR5, death receptor 5; FBS, fetal bovine serum; FCS, fetal calf serum; GPx, glutathione peroxidase; MEHP, mono(2-ethylhexyl)phthalate; NAC, N-acetylcysteine; PBS, phosphate buffered saline; PP peroxisome proliferator; $\operatorname{PPAR} \alpha$, peroxisome proliferator-activated receptor $\alpha$; $\operatorname{PPAR} \gamma$, peroxisome proliferator-activated receptor $\gamma$; ROS, reactive oxygen species; Se, selenium; SM, selenomethionine; SS, sodium selenite; TrxR, thioredoxine reductase.

* Corresponding author. Tel.: +90 3123052178; fax: +90 3123092958.

E-mail address: fhincal@tr.net (F. Hıncal). effectors of the cell cycle (p21/WAF1/Cip1, 14-3-3s, GADD45), apoptosis (Bax1, CD95/APO-1/FAS, AIP1), and DNA repair (p53R2) (Hainaut and Hollstein, 2000; Vousden and Lu, 2002; Fei and El-Deiry, 2003; Hofseth et al., 2004).

p21 was discovered as a "senescent cell-derived inhibitor", binds to the $\mathrm{G}_{1}-\mathrm{S} / \mathrm{CDK}\left(\mathrm{G}_{1}-\mathrm{S} /\right.$ cyclin-dependent kinase, $\left.\mathrm{CDK} 2\right)$ and $S / C D K$ complexes, the molecules important for the $G_{1} / S$ transition in the cell cycle. p21 inhibits the activities of these molecules, and thus functions as a regulator of cell cycle progression at $G_{1}$. The expression of p21 is tightly controlled by p53, through which the p53 protein mediates the p53-dependent cell cycle $G_{1}$ phase arrest in response to a variety of stress stimuli (Harper et al., 1993; Gartel and Radhakrishnan, 2005).

Oxidative stress and reactive oxygen species (ROS) are known to play important roles in many physiological processes (Ames, 1999; Halliwell and Cross, 1994). In contrast, several studies have provided evidence that free radical-induced oxidative damage of cell membranes, DNA and intracellular proteins might be the cause of several degenerative diseases, including cancer (Barnham et al., 2004). The activation of tumor suppressor gene, p53, by a variety of cellular responses including DNA damage pathway induced by ROS has received high importance in the last decade (Ozturk et al., 2009). Several environmental chemicals, including phthalates, 
have been shown to induce apoptosis and senescence in the reproductive tract of rodents through p53 induction (Parmar et al., 1995; McKee et al., 2006).

Di(2-ethylhexyl)phthalate (DEHP), a phthalate derivative and a well-known peroxisome proliferator (PP), is widely used as a plasticizer in the manufacture of PVC plastics. Its widespread use leads to significant human exposures through contaminated foods, food packaging, or medical products (Koo and Lee, 2004; McKee et al., 2004; Silva et al., 2006). DEHP is rapidly metabolized to its major metabolite mono(2-ethylhexyl)phthalate (MEHP) in liver, and MEHP is even more toxic than the parent compound. DEHP disturbs the quality and/or quantity of sperms, induces testicular atrophy in rodents (Parks et al., 2000; Jarfelt et al., 2005; Borch et al., 2006; Erkekoglu et al., 2011), and was shown to increase p21 expression in rat testis (Ryu et al., 2007). MEHP was reported to selectively induce oxidative stress and release cytochrome c from mitochondria in germ cells, thereby inducing apoptosis of spermatocytes and causing testicular atrophy (Kasahara et al., 2002). MEHP was also shown to cause increased p53 stability and elevation of death receptor 5 (DR5) mRNA levels coincident with the increases in the levels of apoptosis in the spermatocytes of C57BL/6 mice (Ryu et al., 2007).

Numerous enzymatic and nonenzymatic antioxidants contribute to cellular protection against oxidative stress, and studies have shown that antioxidants can suppress or delay apoptosis by acting as scavengers of ROS (Zamzami et al., 1995; Ishige et al., 2001). Among other antioxidants, selenium (Se), with its several cellular forms, is involved in the modulation of intracellular redox equilibrium (Oberley et al., 2000; Steinbrenner and Sies, 2009). Low dietary Se intakes in humans are associated with health disorders including oxidative stress-related pathologies, reduced fertility and immune functions (Broadley et al., 2006), and increased risk of cancers (Clark et al., 1991). As a component of the antioxidant enzyme families of glutathione peroxidase (GPx) and thioredoxine reductase (TrxR), Se is involved in the protection of cells from intracellular ROS (Ursini et al., 1995; Mustacich and Powis, 2000). It has been shown that Se could modulate DNA repair in cells with normal p53, and TrxR is required in the reduction of p53 cysteine residues (Seo et al., 2002; Jayaraman et al., 1997).

LNCaP cell line is a good in vitro model for assessing the oxidative stress potential of phthalates as they express prostate specific antigen (PSA), p53 protein, peroxisome proliferator-activated receptor $\alpha$ (PPAR $\alpha$ ), and peroxisome proliferator-activated receptor $\gamma$ (PPAR $\gamma$ ) (Chung et al., 1992). In addition, LNCaP cells have been shown to have responsiveness to inorganic and organic Se compounds [sodium selenite (SS) and selenomethionine (SM)] treatments (Erkekoglu et al., 2010a).

Based on those information and data, this study was designed to examine whether exposure to DEHP or MEHP in LNCaP cells increase ROS production and induce $\mathrm{p} 53$ and $\mathrm{p} 21$ proteins. To investigate the possibility of protective effects of Se in organic and inorganic forms was also aimed.

\section{Materials and methods}

\subsection{Chemicals}

DEHP was obtained from Sigma-Aldrich (St. Louis, MO, USA) and MEHP was from Cambridge Isotope Laboratories (Andover, MA, USA). RPMI 1640 medium and fetal calf serum (FCS) were purchased from GIBCO (Courbevoie, France). 5-(and 6-) chloromethyl-2',7'-dichlorodihydrofluorescein diacetate (CM- $\left.\mathrm{H}_{2} \mathrm{DCFA}\right)$ was purchased from Molecular Probes Detection Technologies, Invitrogen (Eugene, OR, USA). The EnVision Plus staining kit was purchased from Dako (Carpinteria, CA, USA). Primary antibody for p53 (anti-p53) was of mouse origin, monoclonal (sc263) and was obtained from Santa Cruz Biotechnology Inc. (Santa Cruz, USA). Primary antibody for p21 (anti-p21cip1) was of mouse origin, monoclonal (OP64) and was from Calbiochem-Merck KGaA (Darmstadt, Germany). The goat anti-mouse horseradish peroxidase (HRP) conjugated secondary antibody was purchased from
Invitrogen Molecular Probes (Oregon, USA). All the other chemicals including DEHP, SS, SM, fetal bovine serum (FBS), Mayers hematoxylin nuclear stain and saponin from Quillaja bark were obtained from Sigma-Aldrich (St. Louis, MO, USA).

\subsection{Cell culture and treatment}

LNCaP human prostate cancer cell line (lymph-node-derived-androgensensitive cell line, normal for cell-cycle related tumor suppressor genes p53 and retinoblastoma $\mathrm{Rb}$, wild type) was a gift from Prof. Alan Diamond, University of Illinois, USA. The cells were maintained in RPMI 1640 medium containing 5\% FCS, at $37{ }^{\circ} \mathrm{C}$ in a humidified incubator under $5 \% \mathrm{CO}_{2}$. For the experiments, the cells were cultured in RPMI 1640 medium with $10 \%$ FCS and 1\% penicillin/streptomycin in culture flasks in the same conditions and split one-sixth dilution each week.

SS, SM, DEHP and MEHP solutions were prepared as described earlier, and the doses chosen for DEHP ( $3 \mathrm{mM})$ and MEHP $(3 \mu \mathrm{M})$ were previously shown as their approximate $\mathrm{IC}_{50}$ values for LNCaP cells (Erkekoglu et al., 2010a).

Experiments were performed with following treatment groups: NT-C: Nontreated LNCaP cells cultured for $72 \mathrm{~h}$; SS-S: LNCaP cells supplemented and cultured with $30 \mathrm{nM}$ SS for $72 \mathrm{~h}$; SM-S: LNCaP cells supplemented and cultured with $10 \mu \mathrm{M}$ SM for $72 \mathrm{~h}$; DEHP-T: LNCaP cells cultured with $3 \mathrm{mM}$ DEHP for $24 \mathrm{~h}$; SS/DEHP-T: SS-S cells cultured with $3 \mathrm{mM}$ DEHP for $24 \mathrm{~h}$; SM/DEHP-T: SM-S cells cultured with 3 mM DEHP for $24 \mathrm{~h}$; MEHP-T: LNCaP cells cultured with $3 \mu \mathrm{M}$ MEHP for $24 \mathrm{~h}$; SS/ MEHP-T: SS-S cells cultured with $3 \mu \mathrm{M}$ MEHP for $24 \mathrm{~h}$; SM/MEHP-T: SM-S cells cultured with $3 \mu \mathrm{M}$ MEHP for $24 \mathrm{~h}$.

\subsection{Measurement of intracellular ROS production}

Total intracellular ROS production was measured using peroxide sensitive fluorescent probe $\mathrm{CM}-\mathrm{H}_{2}$ DCFA as described earlier (Loikkanen et al., 1998). The study was conducted in the dark, and 70-80\% confluent cells were used. LNCaP cells seeded in 96-well plates with/without SS (30 nM) and SM $(10 \mu \mathrm{M})$ were incubated at $37{ }^{\circ} \mathrm{C}$ in a humidified incubator under $5 \% \mathrm{CO}_{2}$ for $72 \mathrm{~h}$. After removal of the culture media, cells were loaded with $\mathrm{CM}-\mathrm{H}_{2}$ DCFA in phosphate buffered saline (PBS) for $30 \mathrm{~min}$ at room temperature. The cellular esterase activity results in the formation of the non-fluorescent compound, the $2^{\prime}, 7^{\prime}$-dichlorofluorescin (DCFH). DCFH is rapidly oxidized in the presence of ROS to a highly fluorescent $2^{\prime}, 7^{\prime}$-dichlorofluorescein (DCF). The cells were washed, then incubated with with/without DEHP (3 mM) or MEHP $(3 \mu \mathrm{M})$ at $37{ }^{\circ} \mathrm{C}$ in a humidified incubator under $5 \% \mathrm{CO}_{2}$ for 0,30 and 60 min. DCF fluorescence was measured with a Perkin Elmer Victor 31420 multiwell fluorometer (Perkin Elmer, Buckinghamshire, UK) at an excitation wavelength of $485 \mathrm{~nm}$ and an emission wavelength of $535 \mathrm{~nm}$. After data acquisition, Wallac 1420 Manager Software was used to analyze ROS production. Background fluorescence was obtained from cell-free wells containing $5 \mu \mathrm{M}$ DCF in $0.5 \mathrm{~mL}$ of PBS and subtracted from the fluorescence values found. The multiwell plate was kept in a cell culture incubator between the measurements. The exposures were repeated 3-4 times with three parallel measurements. Fluorescence values were normalized to the cell numbers. For each condition, 8-wells were used and the mean was given as a result.

\section{4. p53 and p21 Evaluation by immunocytochemistry}

The expressions of p53 and p21 in LNCaP cells were examined immunocytochemically using specific primary antibodies and the EnVision Plus System. LNCaP cells, treated and cultured as described above, were washed with PBS for $3 \mathrm{~min}$ shaking on a shaker gently, and fixed with $4 \%$ formaldehyde in PBS at room temperature. Cells were rinsed with $\mathrm{ddH}_{2} \mathrm{O}$ once, and washed with PBS for $3 \mathrm{~min}$ as were done between each step, then permeabilized with $\mathrm{PBS} / 0.5 \%$ saponin $/ 0.3 \%$ Triton $\mathrm{X}$ 100 for $3 \times 5$ min on the shaker. Cells were blocked with PBS/10\% FBS/0.3\% Triton $\mathrm{X}-100$ at $37^{\circ} \mathrm{C}$ for $1 \mathrm{~h}$, then PBS washed cells were incubated with diluted primary antibody [for p53 primary antibody was anti-p53, mouse origin, monoclonal (sc263); for p21 primary antibody was anti-p21cip1, mouse origin, monoclonal (OP64)] overnight at $4{ }^{\circ} \mathrm{C}$. HRP conjugated secondary antibody was used directly and cells were incubated at $25^{\circ} \mathrm{C}$ for $30 \mathrm{~min}$. Cells were again washed with $1 \times$ PBS and later with $1 \times \mathrm{PBS} / 2 \% \mathrm{FBS} / 0.3 \%$ Triton X-100 three times, and stained with $3,3^{\prime}$-diaminobenzidine (DAB) chromogen solution. The staining was stopped by adding $\mathrm{ddH}_{2} \mathrm{O}$, and then hematoxylin was used as a nuclear stain. Images were acquired with a DC490 digital camera (Leica, Wetzlar, Germany). Cells were considered to be positive when the staining was present in the nucleus. For each condition three slides were counted and the results were given as percentage of p53 and p21 nuclear stainings.

\subsection{Statistical analysis}

The data were expressed as mean \pm standard error (SEM). Statistical significances of differences among treatment groups were determined by use of oneway analysis of variance and covariance (ANOVA), followed by Student's t-test using a Statistical Package for Social Sciences Program (SPSS) version 17.0. A p-value $<0.05$ was considered as statistically significant. 


\section{Results}

\subsection{ROS production}

The intracellular ROS levels of LNCaP cells measured at different time points are illustrated in Fig. 1. Compared to the initial level, NT-C cells produced no excess level of ROS at time point $30 \mathrm{~min}$; but after $60 \mathrm{~min}$ of incubation, ROS production increased $\sim 1.5$-fold (Fig. 1A). Presence of Se in SS or SM forms did not change
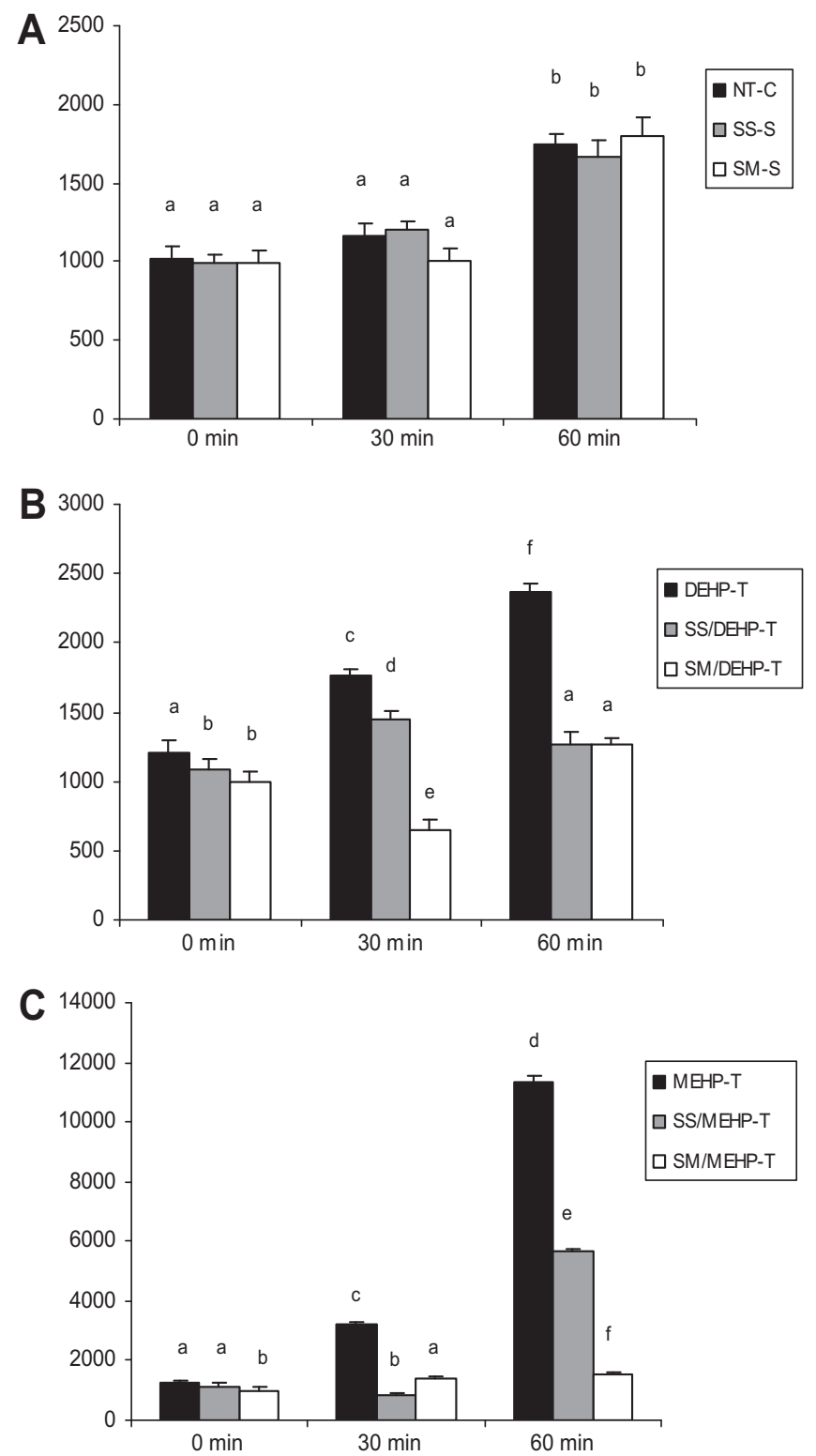

Fig. 1. ROS production in DEHP or MEHP exposed LNCaP cells and effects of selenium supplementation. Total intracellular ROS was measured using peroxide sensitive fluorescent probe $\mathrm{CM}-\mathrm{H}_{2} \mathrm{DCFA}$ at $0 \mathrm{~min}, 30 \mathrm{~min}$, and $60 \mathrm{~min}$. Values are given as mean \pm SEM of $n=3$ experiments and triplicate measurements. Bars that do not share same letters (superscripts) are significantly different from each other $(p<0.05)$. (A) ROS production in cells without phthalate exposure (NT-C: Nontreated LNCaP cells cultured for $72 \mathrm{~h}$; SS-S: LNCaP cells supplemented and cultured with $30 \mathrm{nM}$ SS for $72 \mathrm{~h}$; SM-S: LNCaP cells supplemented and cultured with $10 \mu \mathrm{M}$ $\mathrm{SM}$ for $72 \mathrm{~h}$ ). (B) ROS production in DEHP-treated cells (DEHP-T: LNCaP cells cultured with $3 \mathrm{mM}$ DEHP for $24 \mathrm{~h}$; SS/DEHP-T: SS-S cells cultured with $3 \mathrm{mM}$ DEHP for $24 \mathrm{~h}$; SM/DEHP-T: SM-S cells cultured with $3 \mathrm{mM}$ DEHP for $24 \mathrm{~h}$ ). (C) ROS production in MEHP-treated cells (MEHP-T: LNCaP cells cultured with $3 \mu \mathrm{M}$ MEHP for $24 \mathrm{~h}$; SS/MEHP-T: SS-S cells cultured with $3 \mu \mathrm{M}$ MEHP for $24 \mathrm{~h}$; SM/MEHP-T: SM-S cells cultured with $3 \mu \mathrm{M}$ MEHP for $24 \mathrm{~h}$ ). the intracellular ROS levels at any time compared to those of NT-C cells.

As shown in Fig. 1B, ROS production in DEHP-exposed LNCaP cells increased $\sim 1.5$-fold after $30 \mathrm{~min}$ of incubation, and $\sim 2$-fold after $60 \mathrm{~min}$ compared to the level of time zero $(p<0.05)$. Whereas in MEHP-treated LNCAP cells, very sharp elevation of ROS production was observed reaching $\sim 2$.6-fold and $\sim 9.2$-fold of the initial level, at time points $30 \mathrm{~min}$ and $60 \mathrm{~min}$, respectively (Fig. 1C).

Se supplementation was highly effective against the phthalateinduced ROS generation in LNCaP cells. The protective effects of SS and SM against DEHP-induced intracellular ROS production started right at the beginning; 20\% decrease with SS and 65\% decrease with SM pretreatment were noted at $30 \mathrm{~min}$. Whereas at $60 \mathrm{~min}$, the decrease was $\sim 45 \%$ with both SS and SM and, thus, Se was able to maintain almost the initial level of DEHP-T (Fig. 1B). In MEHP-T cells, SS supplementation caused $\sim 75 \%$ and $\sim 50 \%$ decrease in ROS levels at $30 \mathrm{~min}$ and $60 \mathrm{~min}$, respectively. Se in SM form was more effective providing $\sim 60 \%$ and $\sim 85 \%$ fold decreases at $30 \mathrm{~min}$ and 60 min, respectively (Fig. 1C).

\section{2. p53 Immunocytochemistry}

As shown in Table 1, expression of p53 protein did not change in DEHP-treated LNCaP cells, and Se supplementation did not cause any significant changes either. However, MEHP treatment caused significant increase in p53 expression compared to that of NT-C, and both SS and SM supplementations reduced p53 expression in MEHP-treated cells. The images of nuclear p53 expression in experimental groups are illustrated in Fig. 2.

\section{3. p21 Immunocytochemistry}

The percentage of nuclear p21 stained cells are shown in Table 1. p21 expression did not change by DEHP exposure and selenocompounds did not cause any difference. Whereas, in correlation with the results of p53, MEHP caused a significant increase in p21 expression, and SS and SM supplementations reduced the expression of p21 in MEHP-treated cells but not significantly. The images of nuclear p21 expression are given in Fig. 3.

Table 1

p53 and p21 Immunocytochemistry scorings for the study groups.

\begin{tabular}{lcc}
\hline Study groups & \% of nuclear p53 stained cells & \% of nuclear p21 stained cells \\
\hline NT-C & $6.08 \pm 0.42^{\mathrm{a}}$ & $7.26 \pm 0.72^{\mathrm{ac}}$ \\
SS-S & $5.81 \pm 0.93^{\mathrm{a}}$ & $6.43 \pm 0.73^{\mathrm{a}}$ \\
SM-S & $5.52 \pm 0.17^{\mathrm{a}}$ & $7.23 \pm 1.68^{\mathrm{ac}}$ \\
DEHP-T & $8.55 \pm 0.40^{\mathrm{ab}}$ & $8.63 \pm 0.39^{\mathrm{ac}}$ \\
SS/DEHP-T & $7.39 \pm 1.18^{\mathrm{ab}}$ & $7.89 \pm 0.77^{\mathrm{ac}}$ \\
SM/DEHP-T & $6.36 \pm 0.81^{\mathrm{a}}$ & $8.35 \pm 0.50^{\mathrm{ac}}$ \\
MEHP-T & $10.54 \pm 1.00^{\mathrm{b}}$ & $13.68 \pm 0.86^{\mathrm{b}}$ \\
SS/MEHP-T & $6.63 \pm 2.03^{\mathrm{a}}$ & $9.92 \pm 0.39^{\mathrm{c}}$ \\
SM/MEHP-T & $6.71 \pm 0.40^{\mathrm{a}}$ & $9.71 \pm 0.40^{\mathrm{c}}$
\end{tabular}

p53 and p21 Expressions were determined using EnVision Plus staining kit and special primary antibodies as described in Section 2. Results are given as the percentage of p53 or p21 nuclear stainings (mean \pm SEM). Means within each row that do not share same letters (superscripts) are significantly different from each other $(p<0.05)$.

Measurements were performed in the following treatment groups of cells: NT-C: Non-treated LNCaP cells cultured for $72 \mathrm{~h}$; SS-S: LNCaP cells supplemented and cultured with $30 \mathrm{nM}$ SS for $72 \mathrm{~h}$; SM-S: LNCaP cells supplemented and cultured with $10 \mu \mathrm{M}$ SM for $72 \mathrm{~h}$; DEHP-T: LNCaP cells cultured with $3 \mathrm{mM}$ DEHP for $24 \mathrm{~h}$; SS/DEHP-T: SS-S cells cultured with $3 \mathrm{mM}$ DEHP for $24 \mathrm{~h}$; SM/DEHP-T: SM-S cells cultured with $3 \mathrm{mM}$ DEHP for $24 \mathrm{~h}$; MEHP-T: LNCaP cells cultured with $3 \mu \mathrm{M}$ MEHP for $24 \mathrm{~h}$; SS/MEHP-T: SS-S cells cultured with $3 \mu \mathrm{M}$ MEHP for $24 \mathrm{~h}$; SM/MEHP-T: SM-S cells cultured with $3 \mu \mathrm{M}$ MEHP for $24 \mathrm{~h}$. 

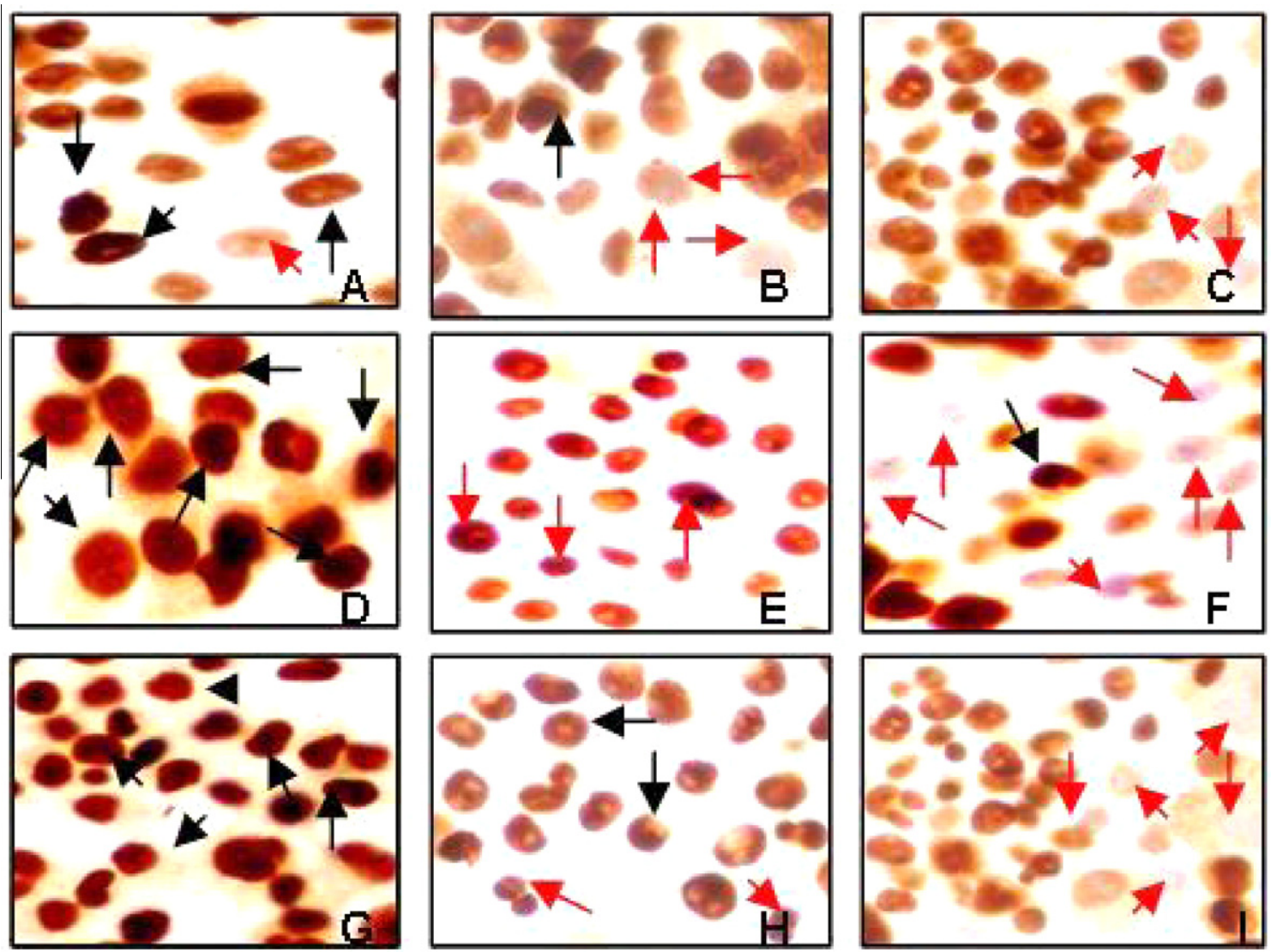

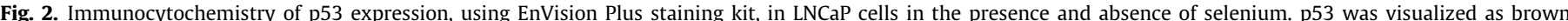

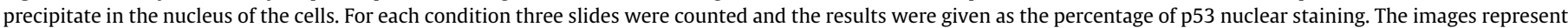

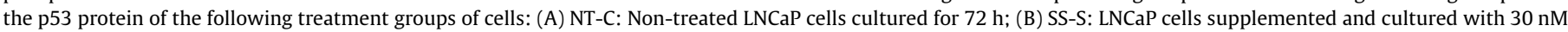

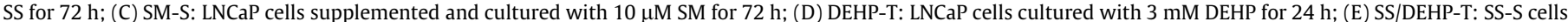

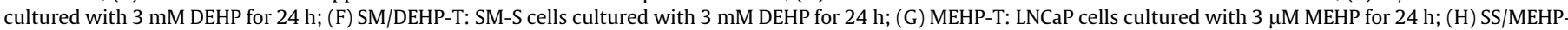

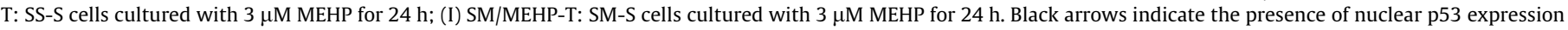
whereas red arrows indicate the absence. (For interpretation of the references to color in this figure legend, the reader is referred to the web version of this article.)

\section{Discussion}

Various modes of action were suggested for the effects of phthalates on the reproductive system. These include dysregulation of gene expression patterns (Borch et al., 2006; Fan et al., 2010), effects on PP-activated receptors and estrogen receptors (Gazouli et al., 2002), and modifications of enzymes that are required in the maturation of sperms (Barlow et al., 2003). Fan et al. (2010) have suggested a new mechanism of MEHP action on Leydig cells streidogenesis via CYP1A1-mediated ROS stress. Being in the same line, the results of a recent study we conducted on MA-10 Leydig cells implicated that at least one of the mechanisms underlying the reproductive toxicity of DEHP and MEHP might be the induction of intracellular ROS and alterations caused in intracellular enzymatic and non-enzymatic antioxidants, thus the production of oxidative stress (Erkekoglu et al., 2010b). We obtained similar results in DEHP- and MEHP-exposed LNCaP cells, and our both studies produced data showing that the two phthalate esters cause significant decreases in cell viability; alter antioxidant status, particularly decrease the GPx1 and TrxR activities; and induce DNA damage as measured by the alkaline Comet assay (Erkekoglu et al., 2010a,b).

ROS operate as intracellular signaling molecules, a function that has been widely documented, but is still controversial. On the one hand, ROS are important intracellular second messengers and involve in the modulation of cell redox state (D'Autréaux and
Toledano, 2007; Veal et al., 2007; Nose, 2000). On the other hand, excessive production of ROS leads to oxidative stress which could subsequently cause loss of cell function and cell death by apoptosis or necrosis, and/or mutagenic and carcinogenic effects (Nose, 2000). In fact, a shift in the prooxidant-antioxidant balance within the prostate has been proposed as a factor that contributes to prostate carcinogenesis (Oberley et al., 2000). The increased intracellular ROS production with phthalate exposure in the current study is the evidence of a shift in the redox equilibrium towards oxidation, thus the occurrence of oxidative stress in LNCaP cells, particularly with MEHP, the hydrolysis product and the main metabolite of DEHP.

As the alterations in the redox status of the cells induced by ROS can cause changes in thiol groups and alter the activation of cell signaling proteins (Finkel, 1998), and p53 tumor suppressor protein is one of those various cell signaling proteins of the cells and known to be redox sensitive (Hainaut and Milner, 1993), the increase we observed in p53 protein expression in MEHP exposed cells was the further evidence for the disturbance of the intracellular redox status. When cells are exposed to oxidative stress, p53 is expressed at high levels by post-translational modifications (Burns and El-Deiry, 1999). These modifications occur rapidly and lead to the activation of p53, resulting in cell cycle arrest or apoptosis. Participation of the p53 protein in the modulation of senescence and apoptosis have been widely described (Munsch et al., 2000; Villunger et al., 2003; Polyak et al., 1997). Even relatively small 

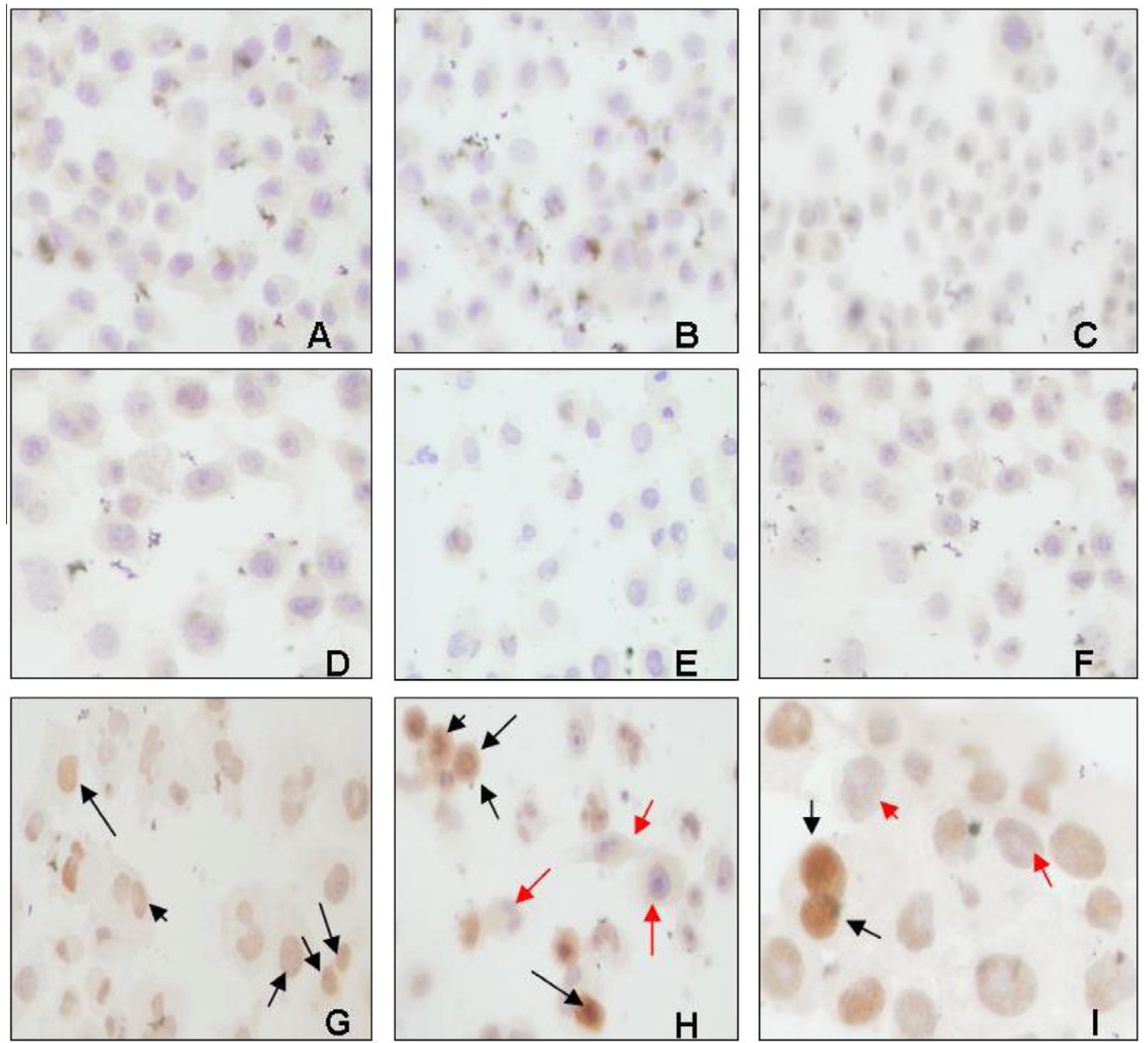

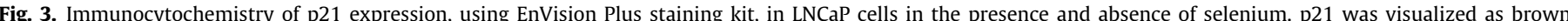

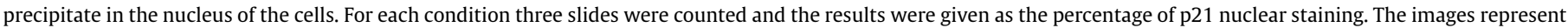

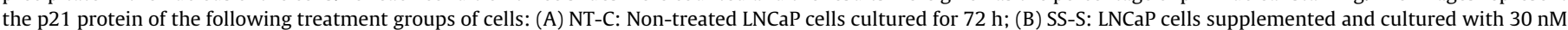

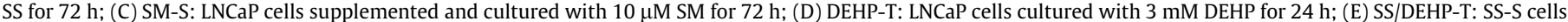

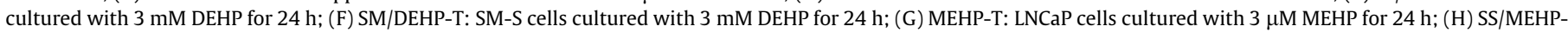

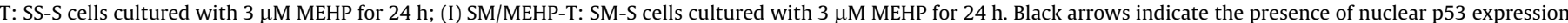

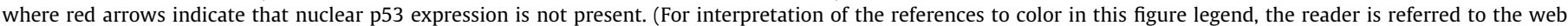
version of this article.)

redox changes may act as modulators of p53 activities and may contribute to shift the balance between various pathways activated in response to p53 (Pluquet and Hainaut, 2001). However, p53 is not only responsive to DNA-damaging agents, but it can be activated by the types of stress which are not primarily genotoxic (Pluquet and Hainaut, 2001).

p53 acts as a checkpoint control protein that determines cellular fate upon DNA damages (Kuerbitz et al., 1992). It can delay the progression of the cell cycle from $G_{1}$ to $S$ phase, thus allowing for repair of DNA damage (Kastan et al., 1991). Alternatively, p53 can trigger apoptosis in response to DNA damage; most probably when the lesions are too extensive and DNA repair fails (Lane et al., 1993). Regarding the induction of apoptosis, we have no data neither in this study nor in our previous studies, but we showed cytotoxic and DNA damaging effects of DEHP and MEHP in LNCaP cells (Erkekoglu et al., 2010a). We also observed similar trends in MA-10 Leydig cells, and we demonstrated the activation of p53 to occur in parallel to DNA damage with MEHP exposure (Erkekoglu et al., 2010b). These data, thus, indicated that the genotoxic potential of the two phthalate derivatives was so high that did not allow the DNA damage to be repaired.

The results of the present study also showed a significant induction of p21 in MEHP-exposed LNCaP cells, in parallel to the induction of p53, suggesting that this might be mediated through the pathway of p53 induction. These data, thus, underscores the importance of p53 and p21 interplay and the link with ROS as the important mediators in cellular response. p21 is the major transcriptional target of the tumor suppressor gene, p53, for the induction of cell cycle arrest following DNA damage (el-Deiry et al., 1993). However, p21 can also be activated by p53-independent pathways to induce senescence or terminal differentiation (Fang et al., 1999; Caffo et al., 1996). A significant increase in p21 expression was reported earlier in the testis of DEHP-receiving rats ( $750 \mathrm{mg} / \mathrm{kg} /$ day for 28 days) which was correlated with DNA fragmentation and along with significantly increased expression of apoptosis-related proteins, like caspase-3, and correlation with DNA fragmentation (Ryu et al., 2007). An increase in p21 expression was shown in livers of DEHP and phenobarbital treated rats 
(Richmond et al., 1996). The difference we observed between DEHP and MEHP with regard to ROS producing potentials, and p53 and p21 activation capacity seemed to be related directly to the individual doses used. It seems that at proper doses the parent compound DEHP itself will produce nuclear p53 activation and p21 induction by producing ROS. In fact, intrinsic toxicity of MEHP is much higher than that of the parent compound (Erkekoglu et al., 2010b; Rhodes et al., 1986).

Our results with Se pre-treated LNCaP cells showed that Se was highly protective against ROS generation induced by DEHP or MEHP exposures. In case of MEHP, both organic and inorganic forms were highly effective but, almost a full protection was provided by the organic Se (SM). We tested the possible protective effect of Se because it is primarily involved in the modulation of intracellular redox equilibrium with its several forms of cellular selenoproteins, and has a critical role in the cellular antioxidant defense (Steinbrenner and Sies, 2009). There are various examples that antioxidants can be beneficial to minimize the detrimental effects of oxidative stress producing toxicants. Fan et al. (2010) demonstrated the inhibition of ROS generation by $\mathrm{N}$-acetylcysteine (NAC) in MEHP-exposed MA-10 cells. In the above-mentioned in vitro studies (Erkekoglu et al., 2010a,b), we demonstrated almost the same level of protection with SS and SM against the antioxidant status modifying effects, DNA damaging effects and cytotoxicity of DEHP and MEHP on MA-10 Leydig cells, as well as LNCaP cells. The results of a recent in vivo study we conducted in DEHPexposed Se-deficient or Se-supplemented rats also demonstrated that the testicular toxicity of DEHP is modified by the Se status, similarly suggesting that the DEHP exposure may cause alterations in the cellular redox state and Se provides protection by the same mechanisms as in the case of testicular cell cultures (Erkekoglu et al., 2011).

In the present study, Se was found to be significantly protective against p53 and p21 activating effect of MEHP. Thus, in the experimental conditions we used, Se supplementation appeared to be an effective redox regulator. However, Se has a narrow therapeutic range and known as bimodal in nature. At low concentrations, selenocompounds are antigenotoxic and anticarcinogenic, whereas at high concentrations, act as pro-oxidants and can be mutagenic and even carcinogenic (Letavayová et al., 2006). In vitro studies have shown that high doses of Se are able to induce apoptosis and inhibit cell growth in transformed cells (Sinha et al., 1996); Se could modulate DNA repair in cells with normal p53 (Seo et al., 2002); and SM was shown to elevate DNA repair and protects cells from DNA damage in the absence of cell cycle arrest or apoptosis (Fischer et al., 2006). The chemical nature of selenium is also critical as it has been demonstrated that inorganic Se is generally more toxic than organic forms, acting mostly on DNA. Whereas, organic Se acts more subtly on various intracellular targets and its effects are more complex (Ip, 1998; Stewart et al., 1999). It appears that the doses and chemical forms of Se we used in this study were appropriate and did not exert any toxicity but provided protection against the oxidant stress inducing effects of DEHP and its metabolite in relation to its intracellular redox modulation.

In conclusion, the overall results of this study demonstrated that DEHP increased intracellular ROS production and activated p53 and p21 in LNCaP cells indicating that the induction of oxidative stress is one of the important mechanisms underlying the toxicity of the compound. These results further suggested that DEHP may affect cell cycle progression through the induction of p53 and subsequently of p21 by mainly the effects of its main metabolite, MEHP. Generated data also emphasized the critical role of Se in the modulation of intracellular redox status. The main implication of these findings is the importance of the appropriate Se status in cellular response against the testicular toxicity of these phthalate derivatives.

\section{Conflict of Interest}

The authors declare that there are no conflicts of interest.

\section{Acknowledgment}

The authors thank to Prof. Alan Diamond for providing the LNCaP cells. Pınar Erkekoğlu, PhD, was a receiver of Erasmus and CEA grants and completed this study at INAC/LAN/CEA and in the Institute Albert Bonniot /UJF, Grenoble, France.

\section{References}

Ames, B.N., 1999. Micronutrient deficiencies. A major cause of DNA damage. Ann N.Y. Acad. Sci. 889, 87-106.

Barlow, N.J., Phillips, S.L., Wallace, D.G., Sar, M., Gaido, K.W., Foster, P.M., 2003. Quantitative changes in gene expression in fetal rat testes following exposure to di(n-butyl) phthalate. Toxicol. Sci. 7, 431-441.

Barnham, K.J., Masters, C.L., Bush, A.I., 2004. Neurodegenerative diseases and oxidative stress. Nat. Rev. Drug Discovery 3, 205-214.

Borch, J., Metzdorff, S.B., Vinggaard, A.M., Brokken, L., Dalgaard, M., 2006 Mechanisms underlying the anti-androgenic effects of diethylhexyl phthalate in fetal rat testis. Toxicology 223, 144-155.

Broadley, M.R., White, P.J., Bryson, R.J., Meacham, M.C., Bowen, H.C., Johnson, S.E. Hawkesford, M.J., McGrath, S.P., Zhao, F.J., Breward, N., Harriman, M., Tucker, M., 2006. Biofortification of UK food crops with selenium. Proc. Nutr. Soc. 65, 169181.

Burns, T.F., El-Deiry, W.S., 1999. The p53 pathway and apoptosis. J. Cell Physiol. 181, 231-239.

Caffo, O., Doglioni, C., Veronese, S., Bonzanini, M., Marchetti, A., Buttitta, F., Fina, P., Leek, R., Morelli, L., Palma, P.D., Haris, A.L., Barbareschi, M., 1996. Prognostic value of p21 (WAF1) and p53 expression in breast carcinoma: an immunohistochemical study in 261 patients with long-term follow-up. Clin. Cancer Res. 2, 1591-1599.

Chung, L.W., Li, W., Gleave, M.E., Hsieh, J.T., Wu, H.C., Sikes, R.A., Zhau, H.E., Bandyk M.G., Logothetis, C.J., Rubin, J.S., 1992. Human prostate cancer model: roles of growth factors and extracellular matrices. J. Cell Biochem. (Suppl. 16H), 99-105

Clark, L.C., Cantor, K.P., Allaway, W.H., 1991. Selenium in forage crops and cancer mortality in US counties. Arch. Environ. Health 46, 37-42.

D’Autréaux, B., Toledano, M.B., 2007. ROS as signalling molecules: mechanisms that generate specificity in ROS homeostasis. Nat. Rev. Mol. Cell Biol. 8, 813-824.

el-Deiry, W.S., Tokino, T., Velculescu, V.E., Levy, D.B., Parsons, R., Trent, J.M., Lin, D., Mercer, W.E., Kinzler, K.W., Vogelstein, B., 1993. WAF1, a potential mediator of p53 tumor suppression. Cell 75, 817-825.

Erkekoglu, P., Zeybek, D., Giray, B., Asan, E., Hincal, F., 2011. Reproductive toxicity of di(2-ethylhexyl)phthalate in selenium-supplemented and selenium-deficient rats. Drug Chem. Toxicol., in press. doi:10.3109/01480545.2010.547499.

Erkekoglu, P., Rachidi, W., De Rosa, V., Giray, B., Favier, A., Hincal, F., 2010a. Protective effect of selenium supplementation on the genotoxicity of $\operatorname{di}(2$ ethylhexyl)phthalate and mono(2-ethylhexyl)phthalate treatment in LNCaP cells. Free Radical Biol. Med. 9, 559-566.

Erkekoglu, P., Rachidi, W., Yuzugullu, O.G., Giray, B., Favier, A., Ozturk, M., Hincal, F., 2010b. Evaluation of cytotoxicity and oxidative DNA damaging effects of di(2-ethylhexyl)phthalate (DEHP) and mono(2-ethylhexyl)phthalate (MEHP) on MA-10 Leydig cells and protection by selenium. Toxicol. Appl. Pharmacol. 248 52-62.

Fan, J., Traore, K., Li, W., Amri, H., Huang, H., Wu, C., Chen, H., Zirkin, B. Papadopoulos, V., 2010. Molecular mechanisms mediating the effect of mono(2-ethylhexyl)phthalate on hormone-stimulated steroidogenesis in MA-10 mouse tumor Leydig cells. Endocrinology 151, 3348-3362.

Fang, L., Lee, S.W., Aaronson, S.A., 1999. Comparative analysis of p73 and p53 regulation and effector functions. J. Cell Biol. 147, 823-830.

Fei, P., El-Deiry, W.S., 2003. p53 and radiation responses. Oncogene 22, 5774-5783. Finkel, T., 1998. Oxygen radicals and signaling. Curr. Opin. Cell Biol. 10, 248-253.

Gartel, A.L., Radhakrishnan, S.K., 2005. Lost in transcription: p21 repression, mechanisms, and consequences. Cancer Res. 65, 3980-3985.

Gazouli, M., Yao, Z.X., Boujrad, N., Corton, J.C., Culty, M., Papadopoulos, V., 2002. Effect of peroxisome proliferators on Leydig cell peripheral-type benzodiazepine receptor gene expression, hormone-stimulated cholesterol transport, and steroidogenesis: role of the peroxisome proliferator-activator receptor alpha. Endocrinology 143, 2571-2583.

Fischer, J.L., Lancia, J.K., Mathur, A., Smith, M.L., 2006. Selenium protection from DNA damage involves a Ref1/p53/Brca1 protein complex. Anticancer Res. 26 899-904.

Hainaut, P., Milner, J., 1993. Redox modulation of p53 conformation and sequencespecific DNA binding in vitro. Cancer Res. 53, 4469-4473.

Hainaut, P., Hollstein, M., 2000. p53 and human cancer: the first ten thousand mutations. Adv. Cancer Res. 77, 81-137.

Halliwell, B., Cross, C.E., 1994. Oxygen-derived species: their relation to human disease and environmental stress. Environ. Health Perspect. 102, 5-12. 
Harper, J.W., Adami, G.R., Wei, N., Keyomarsi, K., Elledge, S.J., 1993. The p21 Cdkinteracting protein $\mathrm{Cip} 1$ is a potent inhibitor of G1 cyclin-dependent kinases. Cell 75, 805-816.

Hofseth, L.J., Hussain, S.P., Haris, C.C., 2004. p53: 25 years after its discovery. Trends Pharmacol. Sci. 25, 177-181.

Ip, C., 1998. Lessons from basic research in selenium and cancer prevention. J. Nutr. $128,1845-1854$.

Ishige, K., Schubert, D., Sagara, Y., 2001. Flavonoids protect neuronal cells from oxidative stress by three distinct mechanisms. Free Radical Biol. Med. 30, 433-446.

Jarfelt, K., Dalgaard, M., Hass, U., Borch, J., Jacobsen, H., Ladefoged, O., 2005. Antiandrogenic effects in male rats perinatally exposed to a mixture of $\operatorname{di}(2$ ethylhexyl)phthalate and di(2-ethylhexyl)adipate. Reprod. Toxicol. 19, 505-515.

Jayaraman, L., Murthy, K.G., Zhu, C., Curan, T., Xanthoudakis, S., Prives, C., 1997. Identification of redox/repair protein Ref-1 as a potent activator of p53. Genes Dev. 11, 558-570.

Kasahara, E., Sato, E.F., Miyoshi, M., Konaka, R., Hiramoto, K., Sasaki, J., Tokuda, M., Nakano, Y., Inoue, M., 2002. Role of oxidative stress in germ cell apoptosis induced by di(2-ethylhexyl)phthalate. Biochem. J. 365, 849-856.

Kastan, M.B., Onyekwere, O., Sidransky, D., Vogelstein, B., Craig, R.W., 1991. Participation of p53 protein in the cellular response to DNA damage. Cancer Res. 51, 6304-6311.

Koo, H.J., Lee, B.M., 2004. Estimated exposure to phthalates in cosmetics and risk assessment. J. Toxicol. Environ. Health, Part A 67, 1901-1914.

Kuerbitz, S.J., Plunkett, B.S., Walsh, W.V., Kastan, M.B., 1992. Wild-type p53 is a cell cycle checkpoint determinant following irradiation. Proc. Natl. Acad. Sci. USA 89, 7491-7495.

Lane, D.P., Midgley, C., Hupp, T., 1993. Tumour suppressor genes and molecular chaperones. Philos. Trans. R. Soc. London B, Biol. Sci. 339, 69-72.

Letavayová, L., Vlcková, V., Brozmanová, J., 2006. Selenium: from cancer prevention to DNA damage. Toxicology 227, 1-14.

Loikkanen, J.J., Naarala, J., Savolainen, K.M., 1998. Modification of glutamateinduced oxidative stress by lead: the role of extracellular calcium. Free Radical Biol. Med. 4, 377-384.

McKee, C.M., Ye, Y., Richburg, J.H., 2006. Testicular germ cell sensitivity to TRAILinduced apoptosis is dependent upon p53 expression and is synergistically enhanced by DR5 agonistic antibody treatment. Apoptosis 11, 2237-2250.

McKee, R.H., Butala, J.H., David, R.M., Gans, G., 2004. NTP center for the evaluation of risks to human reproduction reports on phthalates: addressing the data gaps. Reprod. Toxicol. 18, 1-22.

Munsch, D., Watanabe-Fukunaga, R., Bourdon, J.C., Nagata, S., May, E., YonishRouach, E., Reisdorf, P., 2000. Human and mouse Fas(APO-1/CD95) death receptor genes each contain a p53-responsive element that is activated by p53 mutants unable to induce apoptosis. J. Biochem. 275, 3867-3872.

Mustacich, D., Powis, G., 2000. Thioredoxin reductase. Biochem. J. 346, 1-8.

Nose, K., 2000. Role of reactive oxygen species in the regulation of physiological functions. Biol. Pharm. Bull. 23, 897-903.

Oberley, T.D., Zhong, W., Szweda, L.I., Oberley, L.W., 2000. Localization of antioxidant enzymes and oxidative damage products in normal and malignant prostate epithelium. Prostate 44, 144-155.

Ozturk, M., Arslan-Ergul, A., Bagislar, S., Senturk, S., Yuzugullu, H., 2009. Senescence and immortality in hepatocellular carcinoma. Cancer Lett. 286, 103-113.
Parks, L.G., Ostby, J.S., Lambright, C.R., Abbott, B.D., Klinefelter, G.R., Barlow, N.J., Gray Jr., L.E., 2000. The plasticizer diethylhexyl phthalate induces malformations by decreasing fetal testosterone synthesis during sexual differentiation in the male rat. Toxicol. Sci. 58, 339-349.

Pluquet, O., Hainaut, P., 2001. Genotoxic and non-genotoxic pathways of p53 induction. Cancer Lett. 74, 1-15.

Parmar, D., Srivastava, S.P., Singh, G.B., Seth, P.K., 1995. Testicular toxicity of di(2ethylhexyl)phthalate in developing rats. Vet. Hum. Toxicol. 37, 310-313.

Polyak, K., Xia, Y., Zweier, J.L., Kinzler, K.W., Vogelstein, B., 1997. A model for p53induced apoptosis. Nature 389, 300-305.

Rhodes, C., Orton, T.C., Pratt, I.S., Batten, P.L., Bratt, H., Jackson, S.J., Elcombe, C.R., 1986. Comparative pharmacokinetics and subacute toxicity of $\operatorname{di}(2-$ ethylhexyl)phthalate (DEHP) in rats and marmosets: extrapolation of effects in rodents to man. Environ. Health Perspect. 65, 299-307.

Richmond, R.E., Carter, J.H., Carter, H.W., Daniel, F.B., Deangelo, A.B., 1996. Hepatocyte expression of tumor associated aldehyde dehydrogenase (ALDH-3) and p21 Ras following diethylnitrosamine (DEN) initiation and chronic exposure to $\mathrm{di}(2-$ ethylhexyl)phthalate (DHEP). Carcinogenesis 17, 1647-1655.

Ryu, J.Y., Whang, J., Park, H., Im, J.Y., Kim, J., Ahn, M.Y., Lee, J., Kim, H.S., Lee, B.M., Yoo, S.D., Kwack, S.J., Oh, J.H., Park, K.L., Han, S.Y., Kim, S.H., 2007. Di(2-ethylhexyl)phthalate induces apoptosis through peroxisome proliferators-activated receptor-gamma and ERK $1 / 2$ activation in testis of Sprague-Dawley rats. J. Toxicol. Environ. Health, Part A 70, 1296-1303.

Seo, Y.R., Kelley, M.R., Smith, M.L., 2002. Selenomethionine regulation of p53 by a ref1-dependent redox mechanism. Proc. Natl. Acad. Sci. USA 99, 1454814553.

Silva, M.J., Samandar, E., Preau Jr, J.L., Needham, L.L., Calafat, A.M., 2006. Urinary oxidative metabolites of di(2-ethylhexyl)phthalate in humans. Toxicology 219, 22-32.

Sinha, R., Said, T.K., Medina, D., 1996. Organic and inorganic selenium compounds inhibit mouse mammary cell growth in vitro by different cellular pathways. Cancer Lett. 107, 277-284

Steinbrenner, H., Sies, H., 2009. Protection against reactive oxygen species by selenoproteins. Biochim. Biophys. Acta 1790, 1478-1485.

Stewart, M.S., Spallholz, J.E., Neldner, K.H., Pence, B.C., 1999. Selenium compounds have disparate abilities to impose oxidative stress and induce apoptosis. Free Radical Biol. Med. 26, 42-48.

Ursini, F., Maiorino, M., Brigelius-Flohé, R., Aumann, K.D., Roveri, A., Schomburg, D., Flohé, L., 1995. Diversity of glutathione peroxidases. Methods Enzymol. 252, 38-53.

Veal, E.A., Day, A.M., Morgan, B.A., 2007. Hydrogen peroxide sensing and signaling. Mol. Cell 26, 1-14.

Villunger, A., Michalak, E.M., Coultas, L., Mullauer, F., Bock, G., Ausserlechner, M.J., Adams, J.M., Strasser, A., 2003. p53- and drug-induced apoptotic responses mediated by BH3-only proteins puma and noxa. Science 302, 1036-1038.

Vousden, K.H., Lu, X., 2002. Live or let die: the cell's response to p53. Nat. Rev. Cancer 2, 594-604.

Zamzami, N., Marchetti, P., Castedo, M., Decaudin, D., Macho, A., Hirsch, T., Susin, S.A., Petit, P.X., Mignotte, B., Kroemer, G., 1995. Sequential reduction of mitochondrial transmembrane potential and generation of reactive oxygen species in early programmed cell death. J. Exp. Med. 182, 367-377. 